\title{
A morte de Ivan llitch, de Leon Tolstói: elementos para se pensar as múltiplas dimensões da gestão do cuidado
}

Luiz Carlos de Oliveira Cecilio ${ }^{1}$

CECILIO, L.C.O. The death of Ivan Ilyich, by Leo Tolstoy: points to be considered regarding the multiple dimensions of healthcare management. Interface - Comunic., Saude, Educ., v.13, supl.1, p.545-55, 2009.

The author uses the short story "The Death of Ivan Ilyich", by Leo Tolstoy, to explore the theme of the multiple dimensions of healthcare management (professional, organizational and systemic) by pointing out the omnipresence and complementariness of these dimensions. Although recognizing that there is no hierarchy between these three dimensions, the discussion focuses on the professional dimension, within which professionals meet users, and highlights how this has been the favored territory for management strategies governed by the search for increasing rationality, predictability and control over current health practices, either in the public or in the private healthcare sector. The author points out the risk that "qualification" and "humanization" healthcare programs might be contributing towards instrumentalization and excessive formalization of the meeting point between workers and users, which adds further difficulty to truly caring encounters like the one narrated by Tolstoy in his short story, or even makes them impossible.

Keywords: Healthcare management. Healthcare work. Healthcare micropolicies.
O autor se utiliza do conto A morte de Ivan Ilitch, de Leon Tolstói, para explorar o tema das múltiplas dimensões da gestão do cuidado em saúde (profissional, organizacional e sistêmica), apontando para a imanência e complementaridade que guardam entre si. Mesmo reconhecendo não haver uma hierarquia entre essas três dimensões, focaliza a discussão na dimensão profissional - onde se dá o encontro profissional-usuário destacando como ela tem sido o território preferencial para as estratégias de gerenciamento pautadas pela busca de uma crescente racionalidade, previsibilidade e controle das práticas de saúde, hoje, seja no setor público, seja no setor da saúde suplementar. Aponta para o risco de que programas de "qualificação" e "humanização" do atendimento possam estar contribuindo para a instrumentalização e excessiva formalização do encontro trabalhadorusuário, dificultando ainda mais, senão impossibilitando, encontros verdadeiramente cuidadores como o relatado por Tolstói em seu conto.

Palavras-chave: Gestão do cuidado. Trabalho em saúde. Micropolítica em saúde.
${ }^{1}$ Departamento de Medicina Preventiva, Universidade Federal de São Paulo. Rua Borges Lagoa, 1341. São Paulo, SP, Brasil. 04.038-034 cecilioluiz@uol.com.br 
Assim, a filosofia, a arte e a ciência entram em relações de ressonância mútua e em relações de troca, mas a cada vez por razões intrínsecas. É em função de sua evolução própria que elas percutem uma na outra. Nesse sentido, é preciso considerar a filosofia, a arte e a ciência como espécies de linhas melódicas estrangeiras umas às outras e que não cessam de interferir entre si. (Deleuze, 1992, p.156)

\section{O acontecimento}

Ivan llitch é um juiz que vive na Rússia czarista da segunda metade do século XIX. Ele é o personagem central de um conto de Leon Tolstói (2008) que tem como tema a experiência do adoecer e do morrer, com base na vivência do enfermo. Ivan Ilitch levava uma vida burguesa, dividindo seu tempo entre o trabalho, o convívio com a família e o jogo regular com os amigos. Uma vida sem muitos sobressaltos ou dificuldades, até que, um dia, começa a sentir uma dor no baixo ventre, do lado direito. A dor, que parecia algo passageiro e sem importância, não só persiste, como vai aumentando com o passar do tempo, resistindo aos tratamentos médicos da época. Junto com a dor, há o emagrecimento e uma crescente deterioração física. Progressivamente, Ivan llitch vai tomando consciência da gravidade de seu quadro e de quanto sua antiga vida vai ficando cada vez mais para trás. À medida que o conto avança, somos arrastados, por Tolstói, a compartilhar o sofrimento do personagem. Sem nos darmos conta, aos poucos, começamos a ver os outros personagens, o médico, a família e os amigos, com os olhos do doente. Tolstói, com sua genialidade, nos leva a ocupar "o lugar do doente", a experimentar "estar doente".

Esse lugar do doente, que vamos compartilhando progressivamente, é um lugar terrível por várias razões que se alimentam e se reforçam mutuamente, criando um campo de sofrimento insuportável. Primeiro, pela dor física contínua e crescente, sem trégua. Depois, pela perda de autonomia. A rotina do trabalho que não mais é possível manter, os jogos com os amigos que vão escasseando e o convívio com a família, que já não era muito bom, vai se tornando cada vez mais distante. Perda de controle sobre o modo de viver a vida. Mas o sofrimento de Ivan llitch não para por aqui. Além da dor e da perda da autonomia, o doente vive o tormento do medo da morte. A morte vai assumindo uma materialidade tal que, em dado momento, passa a ser quase uma presença física. Ele passa a conviver com a presença da morte. Dor, perda de autonomia, medo da morte vividos na mais absoluta sensação de desamparo e solidão.

Mas, o pior de tudo, é a incomunicabilidade com os outros. Ninguém parece entender o que ele está vivendo. Os médicos, porque insistem em um linguajar técnico, preocupados em encontrar um diagnóstico da doença e a terapia correspondente. A mulher e os filhos expressam pena e culpa ao vêlo naquela situação. Ele sabe que é um estorvo para a família. O pior, porém, é que ele sabe que todos mentem, que todos fingem não ver o agravamento de sua situação. Seus encontros com o espelho são dramáticos, quase insuportáveis. A imagem que vê em nada faz lembrar o homem que era antes. Ele inveja a vitalidade e a autonomia dos que não estão doentes. Um mundo que the parece cada dia mais distante.

Tal é a situação quando entra um novo personagem em cena: Guerássim, um serviçal, mujique (o camponês russo), analfabeto, é designado para ajudar o patrão quando ele já não consegue mais se cuidar sozinho nas atividades diárias. Guerássim faz a higiene de Ivan llitch quando ele vai ao banheiro, ajuda-o a se levantar e se acomodar na cadeira ou na cama, Ihe traz a comida, ajuda no banho e no desempenho de todas as atividades cotidianas corriqueiras. Atividades que nos parecem tão triviais, mas que, quando estamos doentes, debilitados ou com alguma incapacidade física ou limitação de movimentos, nos parecem tão dramáticas. Tão dramaticamente impossíveis. Tão denunciadoras da nossa perda de autonomia.

Ivan llitch descobriu, por conta própria, que deixar as pernas em posição mais alta, descansando sobre uma almofada, Ihe traz algum alívio para a dor. Um dia, como a dor não havia cedido o bastante com a elevação proporcionada pela almofada, pensa em experimentar usar duas. Pede a Guerássim que levante suas pernas para colocar mais uma almofada. O empregado atende ao seu pedido. Ilitch descobre, então, que a dor praticamente desaparece quando as pernas são levantadas pelo serviçal. Ele pede que 
Guerássim mantenha as pernas bem erguidas mais um pouco. Este experimenta apoiá-las em seu ombro. A sensação de alívio vivida por llitch é maravilhosa. Como se fora uma primeira "intervenção terapêutica" eficaz. Algo que, mesmo paliativamente, Ihe trazia alguma trégua em relação à dor.

A cena passa a se repetir nos dias subsequentes. $O$ ato de colocar as pernas de llitch no ombro de Guerássim vai construindo uma intimidade inimaginável entre um senhor e um servo na Rússia czarista do século XIX. Em um dado momento, o empregado passa a tratá-lo por tu. Um dia, llitch, preocupado com o desconforto do servo, pergunta-lhe se ele não se cansava e se não se importava de manter as pernas naquela posição durante toda a noite. Diante de tal interrogação, Guerássim Ihe responde: "Se não estivesses doente, seria outra conversa; mas, no estado em que estás, por que não te ajudar um pouco?" (Tolstói, 2008, p.73). Progressivamente, o servo dava mostras de ser o único que não mentia e tudo indicava que também era o único a compreender plenamente o que se passava, e não considerava necessário ocultá-lo. "Singelamente condoía-se do patrão tão fraco e esquelético". Um dia, incitado a ir descansar, disse com toda franqueza: "todos nós temos que morrer um dia. Por que não me sacrificar um pouco agora?" (p.74). Disse, explicitamente, que não considerava um fardo tratar de um moribundo e confiava que mereceria o mesmo quando chegasse a sua vez. Pela primeira vez, alguém não lhe mentia. "O que atormentava Ivan Ilitch era que ninguém o lastimasse conforme gostaria de ser lastimado" (p.74). Como diz Tolstói - e aqui vale a pena reproduzir integralmente para que o leitor tenha uma dimensão da sua percepção -,

momento havia, depois de demorados sofrimentos, em que queria, acima de tudo, por mais que se envergonhasse de confessá-lo, ver-se tratado como se fosse uma criança doente. Queria ser acarinhado, mimado, beijado, tal com se faz com as crianças. Sabia que era um juiz importante, dono de uma barba já grisalha e que por isso mesmo o que ambicionava era impossível, mas ainda assim ambicionava. E no comportamento de Guerássim para com ele havia qualquer coisa próxima daquilo que queria e de tal forma sentia-se um pouco confortado. (Tolstói, 2008, p.74)

A doença progride implacavelmente e os médicos cada vez mais impotentes para encontrar uma solução. A mulher relata ao doutor que llitch é rebelde ao tratamento e que "fica numa posição que positivamente não pode the fazer bem: de pernas para cima". Ao que responde o médico: "Que vamos fazer! Os doentes têm mania de inventar uma infinidade de asneiras. Devemos desculpá-los" (Tolstói, 2008 , p.81). O conto termina com o momento da morte, vivida na perspectiva do doente. Um momento de libertação dos medos e de alívio da dor, "e de repente, percebeu com nitidez que aquilo que o atormentara e o oprimia se ia dissipando, escoando para fora de seu corpo por todos os lados ao mesmo tempo" (p.101).

\section{O encontro Ivan Ilitch/Guerássim: elementos de uma micropolítica}

Podemos considerar a micropolítica nas organizações de saúde como o conjunto de relações que estabelecem entre si os vários atores organizacionais, formando uma rede complexa, móvel, mutante, mas com estabilidade suficiente para constituir uma determinada "realidade organizacional" - dessa forma, relativamente estável no tempo, podendo, assim, ser objeto de estudo e intervenção. Os atores são portadores de valores, de projetos, de interesses e disputam sentidos para o trabalho em saúde. É um campo, portanto, desde sempre, marcado por disputas, acordos e composições, coalizões, afetos. Um campo atravessado e constituído por relações de poder. Na micropolítica, há o "racional", mas também o "irracional". Na micropolítica há o que se mostra e o que se diz, mas há o que se oculta e o que não se diz tão claramente. Na micropolítica há liberdade, mas há também determinação. Na micropolítica se veem vetores de mudança, mas também muita conservação. Na micropolítica se produz o cuidado, portanto, os usuários são parte central da micropolítica das organizações de saúde (Cecilio, 2007).

O encontro de llittch com Guerássim não é um encontro de homens "livres". Estão ambos presos a determinações que, em princípio, delimitam suas possibilidades de ação. São atores que se movem em um campo estruturado por uma série de instituídos, a começar pela relação servo-criado, que é a 
materialização, em uma situação particular, de relações sociais que se inscrevem na sociedade russa précapitalista czarista do final do século XIX. O universal encarnado em relações particulares concretas (Lapassade, Lourau, 1972). Relações duras com certeza e que delimitam, em princípio, o campo do POSSÍVEL. Por exemplo, não era possível a um servo se dirigir ao senhor utilizando-se do "tu". Como também, provavelmente, não era possível ou estava fora do imaginável, como norma social, patrão e criado manterem confabulações íntimas sobre suas dificuldades pessoais.

Por outro lado, o espaço do encontro dos dois - um espaço de cuidado - é atravessado pela Instituição Médica que, entre coisas, estabelece o que é certo e o que é errado no cuidado. Basta lembrar como o médico afirma que "os doentes têm mania de inventar uma infinidade de asneiras" ao saber que Ivan Ilitch está com "mania de ficar com as pernas para cima". O médico, falando de seu lugar de saber, desqualifica um modo de cuidar que não é o modo de cuidar da Medicina (Clavreul, 1983). No caso, desconsidera exatamente a única forma de cuidado que foi capaz de trazer alguma ajuda a llitch, à medida que "ficar com as pernas erguidas" não se enquadra nos cânones da Medicina da época, ou pelo menos o que os médicos julgam razoável e científico como cuidado.

No entanto, apesar do encontro de llitch e Guerássim não ser um encontro de homens livres, ser um encontro marcado por "determinações" que lhe são externas, ele comporta, sempre, uma margem de liberdade, de possibilidade de criação, de invenção do inusitado, de atualização do virtual, que escapa aos determinismos que estão presentes na situação. Tal é genialidade de Tolstói ao narrar como, no "espaço intercessor" Ilitch-Guerássim (Merhy, 2002), há a invenção de um novo modo de cuidar que escapa dos instituídos e alarga e reinventa o mundo do possível. Uma "tecnologia de cuidado" que nasce do gesto, da proximidade física, da escuta e da generosidade do "cuidador". A dor de llitch, a necessidade de llitch, o sentido que llitch dá ao seu sofrimento encontrando ressonância, sintonia, resposta por parte do humilde criado. Um momento de empatia (Chacra, 2002). O que ninguém havia conseguido fazer, até então, o servo consegue: inventa junto com llitch uma tecnologia de cuidado com potência para diminuir a dor, reconhece seu medo da morte e fala sobre isso, e lhe dá a atenção de que tanto necessita. Tecnologia levíssima de cuidado. Puro gesto. Contato físico. Descoberta em ato: cuidado/ proximidade/transgressão/criação.

Erguer as pernas em certo ângulo é tecnologia leve de cuidado, algo que não foi aprendido, que não está em nenhum protocolo. Uma invenção de dois sujeitos no seu espaço de encontro. Em ato. $\mathrm{O}$ encontro da Ivan llitch e o movimento generoso de Guerássim. A tecnologia é simples: elevar as pernas, estirar os músculos, distensionar o abdômen. Uma criação a dois. A criação não existiria sem o encontro dos dois personagens: sem a necessidade de llitch e sem a disposição de escutar e ajudar do mujique. Ilitch, o doente, é protagonista na invenção do cuidado necessário. "Paciente" e cuidador são coautores de uma nova forma de cuidado. Esse é o núcleo do conto do Leon Tolstói que pretendo reter para apresentar sobre a complexidade da gestão do cuidado em saúde em suas múltiplas dimensões.

\section{As múltiplas dimensões da gestão do cuidado}

A gestão do cuidado comporta, pelo menos, três dimensões, que poderiam ser representadas por três círculos concêntricos, para expressar a idéia de imanência entre elas: uma "dimensão profissional", uma "dimensão organizacional" e uma "dimensão sistêmica". A primeira dimensão, ou o círculo mais interno de nossa representação, é a gestão do cuidado na esfera de responsabilidade profissional. Ali onde se dá o sempre singular encontro trabalhador-usuário. É a dimensão em que ocorre o fato relatado no conto de Tolstói que estamos analisando. Três componentes são essenciais para a configuração da boa ou má gestão do cuidado na "dimensão profissional" : a postura ética do trabalhador, em particular como ele concebe esse "outro" (o paciente) que necessita de seus cuidados; a competência com que o trabalhador opera o seu "núcleo" de saber, o que nos remete ao maior ou menor domínio técnicocientífico para buscar as melhores respostas para o problema apresentado pelo paciente; a capacidade de criação de um bom vínculo profissional-paciente. Schraiber (1993), ao analisar o trabalho médico, destaca quanto a "boa prática" desses profissionais está pautada por uma dimensão especificamente técnica e uma dimensão "ética", no campo dos valores e das representações, incluindo aí o modo como constrói a sua relação com o paciente - mesmo que a autora destaque quanto tal encontro está atravessado por 
determinações sociais que, em boa medida, configuram o encontro médico-paciente. Merhy (2007), ao escrever sobre o encontro profissional/usuário, enfoca menos as determinações e aquilo que está instituído, e destaca o que tal encontro tem de potência, de possibilidades de criação e de singularidade, ou seja, haveria, sempre, "encontros Ilitch-mujique" potenciais nos serviços de saúde, e a criação/ facilitação de tais encontros poderiam ser vistas como o eixo de qualquer ação gerencial.

O que quero destacar é que há uma dimensão da gestão do cuidado que se realiza no "espaço privado" do encontro trabalhador-usuário. Um espaço de grande potência. O "núcleo duro" da gestão do cuidado. Espaço de irredutível responsabilidade e liberdade de ação do trabalhador. Território-alvo das novas estratégias gerenciais que buscam penetrar esse espaço e moldá-lo de forma heterônoma, seja em uma perspectiva governamental, pelos gestores do SUS, seja numa perspectiva mais empresarial, como no caso do setor da saúde suplementar (ANS, 2004).

A outra dimensão da gestão do cuidado, o "círculo do meio" de nossa representação, é a "dimensão organizacional". Com o irreversível processo de institucionalização das práticas de saúde, a gestão do cuidado, em sua dimensão profissional, desenvolve-se, inapelavelmente, em contextos organizacionais. Uma das características essenciais da transição da medicina liberal para a medicina tecnológica foi exatamente a institucionalização da prática dos médicos, isto é, ela passa a depender, de forma crescente, de contextos organizacionais para o seu exercício (Schraiber, 1993). Novos atores e novas questões vão configurar essa dimensão do cuidado. Trata-se, agora, centralmente, dos desdobramentos da divisão técnica e social do trabalho em saúde, com todas as suas implicações para complexos processos de coordenação de múltiplas práticas profissionais ou das múltiplas "gestões profissionais" do cuidado, para seguirmos com nosso raciocínio. A divisão técnica do trabalho resulta na fragmentação de práticas e exige um custoso esforço gerencial de coordenação dos trabalhos e da comunicação entre os vários profissionais. A divisão social do trabalho resulta em tensões decorrentes das diferentes valorizações - incluindo as remunerações e os status de poder e autonomia - dos diferentes trabalhadores, embora o trabalho de todos seja anunciado como igualmente imprescindível para a "finalização" do cuidado.

$\mathrm{Na}$ "dimensão organizacional" do cuidado vamos, então, nos defrontar com novos e mais variados atores, novas questões, novos desafios e problemas. Se na "dimensão profissional" há um aparente espaço privado, onde se dá o encontro de dois atores (o profissional e o paciente), agora, na "dimensão organizacional" da gestão do cuidado, questões relativas ao registro e uso da informação, à criação de espaços de conversação e troca, ao estabelecimento de fluxos de pacientes, à normalização de processos de trabalho, ao compartilhamento de responsabilidades, entre outros aspectos, vão configurar uma nova lógica em que a responsabilidade gerencial e a conformação da dinâmica de relacionamento da equipe vão ocupar lugar central. A construção de um conjunto de relações mais complexo, se comparado com o encontro trabalhador-usuário, cuja referência segue ainda sendo a "relação médico-paciente" . Não é preciso chamar a atenção para quanto as dimensões profissional e organizacional do cuidado se interpenetram e se condicionam mutuamente. Assim, o trabalho gerencial ideal deverá se ocupar dessas duas dimensões, com suas especificidades e, ao mesmo tempo, notável interdependência.

Por fim, nosso último círculo, o mais externo de todos, representa a "dimensão sistêmica" da gestão do cuidado. A gestão do cuidado pode ser pensada, em uma perspectiva sistêmica, como o conjunto de serviços de saúde, com suas diferentes funções e diferentes graus de incorporação tecnológica e os fluxos que se estabelecem entre eles. Tais fluxos serão definidos por protocolos, controlados por centrais de vagas ou de marcação de consulta, sempre na perspectiva de garantir o acesso dos usuários às tecnologias de cuidado de que necessitam, por meio da constituição e gestão de complexas "redes de cuidado" institucionais, operadas por intermédio de processos formais de referência e contrarreferência, que propiciem a circulação das pessoas por um conjunto articulado de serviços de saúde, de complexidades diferentes e complementares entre si. Este é, em princípio, um mundo razoavelmente estruturado, regido por regras e responsabilidades, e que pode ser objeto de gestão (coordenação, avaliação e controle). A visão sistêmica da gestão do cuidado, como expresso de forma mais recente no Pacto pela Vida (Brasil, 2006), é imprescindível para a consolidação do SUS, mas - e este é o ponto que quero destacar -, não será nunca suficiente se não for enriquecida com outras perspectivas ou o reconhecimento de sua imanência com as outras dimensões do cuidado que desenvolvemos até agora. 
Para além das regularidades sistêmicas, seria útil pensar a gestão do cuidado que resultasse na integralidade da atenção buscada pelas pessoas, por tudo o que vimos até agora, como fruto de uma incontável rede de encontros. Encontros nos nós de uma complexa rede de cuidado. Os nós da rede são conexões humanas, são encontros humanos. Há um potencial imenso de energia-criatividadeprodução retida nos nós. Quanto mais esses encontros se aproximarem de um acontecimento como foi o encontro llitch-Guerássim, mais criação será possível, mais cuidado, mais linhas de fuga em relação às determinações presentes em tais encontros.

\section{Interrogações sobre a gestão do cuidado que o texto de Leon Tolstói nos provoca}

Haveria modos de se fazer a gestão cuja lógica fosse ajudar a liberar a potência criadora retida nos nós da rede? O gestor poderia pretender entrar nesse campo sem correr o risco de torná-lo ainda mais estruturado e capturante? Seria possível inventar práticas gerenciais que conseguissem abrir esses espaços de encontro, sem destruir o que precisam ter de espontaneidade e liberdade? É possível tomar estes espaços de encontros como objeto de práticas gerenciais? Se afirmativo, quais os saberes que precisariam ser mobilizados? Não é difícil imaginar que questões referentes ao campo da ética, da visão de mundo, da construção da autonomia individual e coletiva, em um mundo atravessado por determinações e constrangimentos, estarão sempre presentes ao tentarmos responder tais questões. Será sempre um mundo em disputa de sentidos, uma triangulação sempre tensa dos interesses dos trabalhadores, usuários e gerentes/gestores.

Voltando ao mujique cuidador: qual seria o segredo de tal encontro no qual se dá o cuidado mais genuíno? Como um serviçal ignorante e analfabeto consegue escutar, de forma radical e criativa, a necessidade de cuidado do outro, conseguindo, assim, aliviar a dor, entender o medo e confortar Ivan Ilitch? Imaginemos uma complexa rede de serviços em que tais encontros se reproduzissem em grande escala. Isso seria possível? Que trabalhador seria necessário "produzir" para sustentar, construir tais encontros? Será que a racionalidade instrumental que caracteriza as organizações formais - com suas metas, sua missão, seus recursos escassos, seus conflitos de interesses, suas hierarquias de autoridade, suas relações de dominação e violência - suportam conviver com a espontaneidade e generosidade da relação entre Ivan llitch e o mujique? É possível a generosidade na dureza das organizações formais?

Apontei, antes, que nossos dois personagens não eram homens "livres", mas presos a regras sociais e determinações institucionais muito rígidas. O campo em que se constrói a relação relatada por Tolstói, e que nos encanta, é atravessado por instituições muito fortes: a medicina, as relações de classe, a família. Como, em campo tão marcado, nasce uma forma de cuidado tão criativa e generosa? E se supusermos que houvesse um profissional de saúde "supervisionando" e ditando os "procedimentos corretos", exigindo o cumprimento de "protocolos de cuidado", estabelecendo de maneira precisa o que é certo e o que é errado, a relação teria acontecido na forma em que se deu? Basta lembrar que o médico desqualificou o ato de erguer as pernas, não reconhecendo nele nenhuma "validade terapêutica", ao dizer: "Que vamos fazer! Os doentes têm mania de inventar uma infinidade de asneiras. Devemos desculpá-los".

Penso, também, ser correto supor que há incontáveis encontros Ivan-mujique acontecendo na rede de serviços. Anônimos, não reconhecidos, a não ser, é claro, por aqueles que são cuidados. Na quase brutalidade das relações cotidianas das organizações de saúde (demanda sem fim, precárias condições de trabalho das equipes, gerências despreparadas e autoritárias etc.) produz-se cuidado, produzem-se sentidos que escapam a qualquer lógica gerencial normalizadora e controladora (Cecilio, 2007).

Reconhecendo que há muitos bons encontros cuidadores que acontecem sem o (re)conhecimento e a intervenção da gerência, o problema que se nos impõe é: e quando os encontros não são cuidadores? Quando quem procura os serviços de saúde não encontra o que precisa: escuta, atenção e resolutividade para seus problemas? Quem pode detectar que isso está ocorrendo, às vezes de forma sistemática e em vários pontos do sistema? Em pontos obscuros do sistema, ali onde os trabalhadores desenvolvem suas práticas em espaços quase privados, no sentido de não serem alcançados pelo olhar do gestor. Interrogar tais espaços intercessores, espaços Ilitch/mujique, pode ser objeto da gestão em saúde? Essa é a interrogação central de meu texto. 


\section{A "dimensão profissional" da gestão do cuidado é o alvo das estratégias gerenciais}

É fácil reconhecer quanto os esforços institucionais empreendidos na direção da qualificação do atendimento - como definida pelas direções/gerências dos serviços de saúde - têm se baseado na criação de protocolos, de capacitações, de estabelecimento de normas, regras, fluxos e rotinas destinados a "modelar" comportamentos dos trabalhadores, tendo como alvo, justamente, o que denominei do "núcleo duro" da gestão do cuidado, ou seja, a "dimensão profissional". São estratégias que buscam dar visibilidade, regulamentar, moldar, padronizar o encontro trabalhador-usuário para que critérios de eficácia e eficiência sejam alcançados. Estratégias gerenciais que se destinam, em última instância, a conferir visibilidade, padronização e previsibilidade ao espaço "privado" de tal encontro.

O que torna muito complexo o processo da gestão do cuidado, quando pensado em uma perspectiva mais abrangente e articulada como "sistema de saúde", seja ele o próprio SUS ou os "sistemas de saúde", que são as operadoras de planos de saúde, é o fato de que as várias lógicas da gestão do cuidado são operadas na perspectiva de múltiplos atores, que, a partir de seus lugares institucionais, seus interesses e dos sentidos que dão às suas práticas, vão produzindo "vetores" (de sentido/ação) que nem sempre se alinham automaticamente à única pretensa macrorracionalidade organizacional. Basta lembrar que, em cada uma das dimensões, há algum ator ou atores que assumem papel diferenciado na gestão do cuidado: o profissional construindo a relação profissional-paciente, o gerente construindo a equipe que cuida e provendo os insumos para seu trabalho, e o gestor construindo as redes de cuidado.

Como vimos, as várias dimensões do cuidado se interpenetram. As redes de cuidado que o gestor tem sob sua responsabilidade construir, por exemplo, dependem intimamente do modo como a gestão do cuidado é feita nas outras dimensões. A eterna insuficiência ou a inesgotável demanda por serviços de média e alta complexidade, todos sabem, depende muitíssimo de como a gestão do cuidado é feita pelo profissional e pela equipe. O outro lado da moeda: o cuidado ao paciente, feito pelo profissional, é altamente dependente do trabalho da equipe e de quanto o "sistema" pode ou não oferecer as tecnologias para que o cuidado se "finalize".

Assim, as estratégias gerenciais de disputa de sentidos da gestão do cuidado em sua dimensão profissional terão de dar conta, de forma sinérgica, de um duplo movimento: em uma lógica transversal, cuidar de uma articulação mínima das três esferas de gestão no sentido de conformação de "sistemas de saúde" razoavelmente estruturados e permeáveis às necessidades dos usuários e dos profissionais; e, ao mesmo tempo, em uma lógica mais focal, desenvolver estratégias específicas para o núcleo profissional, no sentido de "interrogá-lo" e promover sua integração às diretrizes ou "políticas de saúde", tanto do campo público-estatal como das operadoras dos planos privados de saúde.

Portanto, não seria demais afirmar que os atores que estão em situação de governo ou de direção superior, sejam eles dirigentes público-estatais ou executivos das operadoras, se deparam com o mesmo problema crucial, que é o de desenvolver a capacidade de, em alguma medida, obter certo controle sobre a dimensão profissional da gestão do cuidado, questionando o grau de autonomia com que ela tem sido historicamente operada, em particular quando se trata do profissional médico.

Penso ser possível trabalhar com a idéia de que, no atual contexto da gestão em saúde, duas estratégias polares têm sido experimentadas na perspectiva da abertura do "núcleo profissional" da gestão do cuidado. Poderíamos designá-las, de forma simplificada, como "estratégias instrumentais" e "estratégias de base comunicativa". As primeiras se caracterizariam por uma concepção instrumental do trabalho em saúde, o qual é visto como meio ("instrumento") para o alcance de determinados fins, projetos ou políticas estabelecidos pelo gestor. "Gestão de recursos humanos" e, mais recentemente, "gestão de pessoas", expressam bem essa forma de pensar o trabalho em saúde. Uma vez que os fins, os objetivos/metas e as finalidades do trabalho em saúde são estabelecidos pela direção superior, com base em seus interesses estratégicos, políticos e financeiros, todo o processo de gestão, via mediação de gerências intermediárias "fiéis" e bem capacitadas, se concentraria no COMO alcançar tais fins, objetivos e finalidades, isto é, o trabalho em saúde seria um meio ("instrumento") para alcançar determinados fins. Por isso, a designação de estratégia instrumental. As estratégias de base 
comunicativa, por sua vez, assentam-se no princípio de que tanto as finalidades, objetivos e sentidos do trabalho em saúde, como os meios para alcançá-los devem ser construídos por meio de intenso, regular e sistemático processo de negociação, conversação, convencimentos, criação de consensos, entre os vários atores institucionais, lançando-se mão, para isso, de um conjunto de estratégias gerenciais de orientação mais comunicativa, com especial destaque para a idéia de cogestão dos serviços pelos trabalhadores e direção.

Isto posto, é necessário que se façam dois esclarecimentos. O primeiro é que, em princípio, a cada uma de tais estratégias corresponderiam modos distintos de se fazer a gestão. Enquanto seria possível associar ao paradigma instrumental um modo de se fazer a gestão mais "autoritário", vertical ("topobase") e heterônomo, no sentido de ser mais controlador e mais capturador da autonomia dos trabalhadores, ao paradigma de base comunicativa estariam associados modos mais "democráticos" e participativos de se fazer a gestão. O segundo esclarecimento vem quase no sentido de negar o primeiro, ao afirmarmos que tais estratégias nunca poderão ser encontradas como formas puras, como tipos-ideais weberianos (Weber, 1991). Nas condições reais do processo de gestão, as duas estratégias quase sempre se apresentam de forma mesclada. Um componente comunicativo há de existir sempre, mesmo nos modos mais instrumentais de se fazer a gestão, tendo em vista a incontornável necessidade de alguma negociação com os trabalhadores de saúde, por conta do seu protagonismo, da defesa que fazem de algum grau de autonomia no controle do seu trabalho e, não menos importante, pelo fato de que os trabalhadores são produtores, sobretudo por suas pertenças profissionais, de sentidos para o seu trabalho irredutíveis aos sentidos que a direção pretende impor. Por outro lado, mesmo nas propostas ditas mais democráticas, participativas, em grau menor ou maior, sempre será possível reconhecer alguma instrumentalização ou "funcionalização" dos trabalhadores pelos dirigentes, no sentido apontado acima. Como reconhece Campos (2007), "Não há trabalho em ato (vivo) que não se apóie em algum trabalho prévio (morto). O desafio estaria em lidar com este fato inexorável e não prometer ou sugerir a possibilidade de fluxos espontâneos em que haveria criação ex-nihil. Nesse sentido, admito que todo trabalhador, em alguma medida, estará obrigado a assumir algum grau de 'funcionalidade'. Todos somos, em algum grau, 'trabalhadores funcionais' à organização, às necessidades e interesses dos outros, sejam usuários ou colegas de equipe".

O managed care (atenção gerenciada), tal como proposto e experimentado nos Estados Unidos, na década de 1990, talvez possa ser lembrado como exemplo mais expressivo de uma estratégia gerencial de base claramente instrumental visando o núcleo profissional da gestão do cuidado, na qual o dinheiro entra como elemento externo para intervir, regular e modificar o núcleo mais "interno" de todo o processo de gestão do cuidado (Iriart, 1999). O mais provocativo na atenção gerenciada é quanto ela toma como alvo exatamente a relação médico-paciente, cuja "privacidade" pode ser considerada como elemento constitutivo da prática médica (Schraiber, 1993).

Por outro lado, modos de gestão assentados em uma concepção mais negociada e dialógica entre direção e conjunto dos trabalhadores, com forte ênfase no funcionamento de colegiados de gestão e outros dispositivos de encontro e negociação dos trabalhadores entre si e dos trabalhadores e direção, intencionalmente construídos como espaços de formulação e acompanhamento das políticas, frequentemente sofrem algum grau de instrumentalização pelos gestores, o que é rapidamente percebido pelos trabalhadores, que desenvolvem estratégias de resistência às propostas "participativas", como apontado em trabalhos anteriores (Cecilio, 2004).

De qualquer forma, o que vemos, hoje, de forma marcante, são: a valorização e a utilização de modelos gerenciais pautadas no uso intensivo de informação e sofisticados processos de avaliação, dos quais nenhum ator institucional escapa; a compulsiva protocolização de práticas e a regulamentação de processos de trabalho; uma grande preocupação com a "sensibilização" e a educação continuada dos trabalhadores, bem como o avanço do "gerencialismo" (Vieira, Carvalho, 1999), isto é, a adoção de métodos e práticas de gestão do setor privado no setor público, tudo isso caracterizando o que alguns autores têm chamado da racionalização crescente das práticas de saúde (Carapinheiro, 1998). 
Talvez não seja demais afirmar que

[...] o gerencialismo, se adotado de modo acrítico, sem considerar as características do setor público, poderá ter graves conseqüências para o funcionamento dos serviços de saúde, em particular porque pode resultar na exacerbação da lógica instrumental normalmente presente em todas as organizações e, em conseqüência, em aumento das tensões e conflitos e do sofrimento dos trabalhadores e, em última instância, na própria piora da atenção prestada, se considerarmos que, na saúde, o sucesso desse encontro trabalhador-usuário depende, em boa medida, de um clima organizacional mais distensionado. (Cecilio, 2007, p.253-4)

Por tudo o que vimos até agora, é possível dizer que, no atual estágio de institucionalização das práticas de saúde, o encontro profissional-paciente tem sido, cada vez mais, alvo de estratégias gerenciais que disputam o sentido e a dinâmica de tal encontro. O encontro llitch-mujique assume, portanto, nas atuais condições de operação dos sistemas de saúde, uma complexidade bem maior que o conto de Leon Tolstói permite antever. O fato de o encontro trabalhador-usuário ser alvo de cada vez mais sofisticadas estratégias de modelagem das práticas dos primeiros, pode nos levar a uma visão bastante crítica e pessimista dos processos gerenciais em curso, se nossa intenção for favorecer encontros Ilitch-mujique que sejam presididos por tecnologias leves de cuidado (Merhy, 2002), produzidas em ato, facilitando uma convergência das necessidades dos usuários com prática de "trabalhadores mujiques". Trabalhadores generosos, capazes de fazer uma escuta qualificada do que o OUTRO, que está na sua frente, Ihe apresenta; e, o que é mais importante, tanto disponibilizar o que já sabe para melhorar a vida desse OUTRO, como ser capaz ou estar aberto para a invenção de novas formas de cuidado adequadas a cada situação singular. Tratar-se-ia, portanto, da possibilidade de se construírem práticas gerenciais que valorizem as "linhas de fuga" que escapam ao que está instituído e sacramentado pelos saberes que operam os serviços de saúde, possibilitando uma escuta mais fina das necessidades singulares de cada pessoa.

Por tudo isso é que a interrogação que fiz antes - qual seja: como desatar a energia e a criatividade retida nos "nós" da rede de encontros, produzindo mais saúde e autonomia dos usuários?, como no encontro descrito por Tolstói - permanece em aberto quando finalizo minhas reflexões. Talvez seja correto dizer que ela permanece como o tema central da gestão hoje, quando pensada com base em uma perspectiva crítica. Diante da deterioração das relações nos serviços de saúde, de práticas cada vez mais serializadas e impessoais de cuidado, do angustiante "diálogo de surdos" entre profissionais e pacientes, da baixíssima capacidade para dar respostas mais complexas e matizadas às necessidades de saúde portadas pelos usuários, a imagem comovedora do rico encontro Ilitch/Guerássim funcionaria como um fugidio e, cada vez mais distante, ideal a ser alcançado.

No seu lugar, parece-nos cada vez mais tentadora - e, o que é pior, aparentemente a única saída visível - a adoção de práticas gerenciais que se destinam a disciplinar, normalizar, padronizar a dimensão profissional da gestão do cuidado, impondo modos taylorizados de cuidado, por trabalhadores adestrados, controlados, rigorosamente capacitados para o exercício de suas funções. Trabalhadores executando funções perfeitamente projetadas e desencarnadas de qualquer contradição, falha, imperfeição e tudo o mais que, afinal, dá a dimensão humana de cada um de nós.

Philippe Meyer (2003), ao descrever, de forma ficcional, um hospital que está sendo inaugurado às margens do Sena, em Paris, pela Comunidade Econômica Européia, em 2033, parece antever, de forma muito sensível, possíveis desdobramentos dos atuais vetores de racionalização das práticas de saúde, ao enumerar algumas das características do hospital do século XXI: "Uma medicina oferecida em amplas instituições dominadas pela ciência e pela técnica, privada de enfermeiras e exercidas por médicos esfalfados pela velocidade da ciência, sobrecarregados por inúmeras obrigações administrativas que exigem mais tempo do que o exercício da medicina" (Meyer, 2003, p.64). 
E fala, também, de uma "nova era de solidão no hospital". E, como afirma o autor: "Isolamento agravado pela informatização dos dossiês e de alguns tratamentos, pela insuficiência quantitativa das fontes de compaixão e pela absorção dos médicos em tarefas cada vez mais numerosas e que não estão diretamente ligadas ao atendimento" (Meyer, 2003, p.64).

Afora essas indicações de uma obra ficcional, o que resultará do triunfo de tais estratégias instrumentais ainda permanece em aberto no atual estágio de conhecimento. Diante do grau de desorganização, desumanização e ineficiência que boa parte dos sistemas e serviços de saúde têm operado hoje, com terríveis consequências para seus usuários, é justo pensar que, a curto prazo, o triunfo do gerencialismo e da exacerbação das tecnologias de gestão mais instrumentais possa resultar em benefícios para quem precisa de cuidados em saúde. Fica, porém, a dúvida sobre quanto tais conquistas de curto prazo poderão, no futuro, contribuir para que se (re)inventem novas formas de cuidado e novos modos de encontros trabalhadores-usuários que resultem na potência, criação e reinvenção do humano, que tanto nos encantam no encontro llitch-Guessárim.

\section{Referências}

AGÊNCIA NACIONAL DE SAÚDE SUPLEMENTAR - ANS. Duas faces da mesma moeda: microrregulação e modelos assistenciais na saúde suplementar. Rio de Janeiro, Ministério da Saúde: ANS, 2005. (Série A, Normas e Manuais Técnicos - Regulação e Saúde 4).

BRASIL. Ministério da Saúde. Secretaria-Executiva. Departamento de Apoio à Descentralização. Regionalização solidária e cooperativa: orientações para sua implementação no SUS. Brasília: Editora MS, 2006. v.3. (Série Pactos pela Saúde)

CAMPOS, G.W.S. Comentários sobre analogias e diferenças entre os métodos Paidéia e o "interrogativo". Interface - Comunic., Saude, Educ., v.11 n.22, p.352-4, 2007.

CARAPINHEIRO, G. Saberes e poderes no hospital: uma sociologia dos serviços hospitalares. Porto: Afrontamento, 1998.

CECILIO, L.C.O. A micropolítica do hospital: um itinerário ético-político de intervenções e estudo. 2007. Tese (Livre-docência) - Universidade Federal de São Paulo, São Paulo. 2007.

CECILIO, L.C.O.; MENDES, T.C. Propostas alternativas de gestão e protagonismo dos trabalhadores: por que as coisas nem sempre acontecem como os dirigentes desejam? Saude Soc., v.13, p.39-55, 2004.

CHACRA, F.C. Empatia e comunicação entre o esforço de existir e a ética imanente: uma semiologia autopoiética do vínculo na relação médico-paciente. 2002. Tese (Doutorado) - Departamento de Medicina Preventiva e Social, Universidade Estadual de Campinas, Campinas. 2002.

CLAVREUL, J. A ordem médica: poder e impotência do discurso médico. São Paulo: Brasiliense, 1983.

DELEUZE, G. Conversações. São Paulo: Editora 34, 1992. 
IRIART, C.B. Atenção gerenciada: instituinte da reforma neoliberal. 1999. Tese (Doutorado) - Departamento de Medicina Preventiva e Social, Universidade Estadual de Campinas, Campinas. 1999.

LAPASSADE, G.; LOURAU, R. Chaves da sociologia. Rio de Janeiro: Civilização Brasileira, 1972.

MEYER, P. A irresponsabilidade médica. São Paulo: Editora Unesp, 2003.

MERHY, E.E. Gestão da produção do cuidado e clínica do corpo sem órgãos: novos componentes dos processos de produção do cuidado em saúde. Disponível em: <http:/www.hucff.ufrj.br/micropolitica/ 2007> . Acesso em: 18 maio 2008.

Apêndice 3. Todos os atores em situação, na saúde, disputam a gestão e produção do cuidado.. In: Hucitec, 2002. p.149-78. . Saúde: a cartografia do trabalho vivo. São Paulo:

SCHRAIBER, L.B. O médico e seu trabalho: limites da liberdade. São Paulo: Hucitec, 1993.

TOLSTÓı, L. A morte de Ivan Ilitch. Porto Alegre: L\&PM Pockt, 2008.

VIEIRA, M.M.F.; CARVALHO, C.A.P. Qualidade e objetivos: implicações teóricas e metodológicas para a análise das organizações. In: VIEIRA, M.M.F.; OLIVEIRA, L.M.B. (Orgs.). Administração contemporânea: perspectivas estratégicas. São Paulo: Atlas, 1999. p.121-47.

WEBER, M. Economia e sociedade: fundamentos da sociologia compreensiva. Brasília: Editora UnB, 1991. v.1.

CECILIO, L.C.O. La muerte de Ivan Illitch, de León Tolstoi: elementos para considerar las múltiples dimensiones de la gestión del cuidado. Interface - Comunic., Saude, Educ., v.13, supl.1, p.545-55, 2009.

El autor utiliza el cuento La muerte de Ivan Illitch, de León Tolstoi, para explorar el tema de las múltiples dimensiones de la gestión del cuidado en salud (profesional, de organización y sistémica) apuntando hacia la inherencia y complementación que guardan entre si. Aunque reconociendo que no hay una jerarquía entre esas tres dimensiones, enfoca la discusión en la dimensión profesional - donde se da el encuentro profesional - usuario - destacando como ha sido el territorio preferente para las estrategias de administración pautadas por la búsqueda de una creciente racionalidad, previsión y control de las prácticas de salud actuales, ya en el sector público, ya en el sector de la salud suplementaria. Señala el riesgo de que programas de "calificación" y "humanización" del atendimiento puedan estar contribuyendo a la instrumentación y excesiva formalización del encuentro trabajador - usuario, dificultando aún más, sino imposibilitando, encuentros verdaderamente cuidadores como el relatado por Tolstoi en su cuento.

Palabras clave: Gestión del cuidado. Trabajo en salud. Micro-política en salud. 